\title{
Breast-Milk lodine Concentrations, lodine Status, and Thyroid Function of Breastfed Infants Aged 2-4 Months and Their Mothers Residing in a South African Township
}

\author{
Jennifer Osei1, Maria Andersson2, Olivia van der Reijden2, Susanne Dold2, Cornelius M. Smuts1, \\ Jeannine Baumgartner ${ }^{1}$
}

${ }^{1}$ North-West University, Centre of Excellence for Nutrition, Potchefstroom, South Africa

2ETH Zurich, Human Nutrition Laboratory, Institute of Food, Nutrition, and Health, Zurich, Switzerland

\section{WHAT IS ALREADY KNOWN ON THIS TOPIC?}

South African school children and women of reproductive age have adequate iodine intake. However, more recent data point gaps in iodine nutrition of South Africans, as more than a third of the population still lacks access to adequately iodized salt. Furthermore, no data exist on iodine status in lactating women and infants. Breast-milk iodine concentrations are dependent on maternal iodine intake.

\section{WHAT THIS STUDY ADDS?}

This is the first study to report iodine status, breast-milk iodine concentrations (BMIC), and thyroid function of breastfed infants and lactating mothers in South Africa. lodine in household salt (SIC) and maternal urinary iodine concentration (UIC) were predictors of BMIC, which in turn predicted the UIC of infants. Our results indicate a successful universal salt iodization program in South Africa providing adequate iodine for infants via breast milk. However, fortification of salt needs to be monitored, to avoid over-iodization of salt.

\section{ABSTRACT}

Objective: Lactating women and their infants are susceptible to iodine deficiency and iodine excess. In South Africa, no data exist on the iodine status and thyroid function of these vulnerable groups.

Methods: In a cross-sectional study, urinary iodine concentrations (UIC), thyroid function, and breast-milk iodine concentrations (BMIC) were assessed in 100 lactating women from a South African township and their 2-4-month-old breastfed infants. Potential predictors of UIC, thyroid function, and BMIC, including household salt iodine concentrations (SIC) and maternal sodium excretion, were also investigated.

Results: The median (25th-75th percentile) UIC was 373 (202-627) $\mu \mathrm{g} / \mathrm{L}$ in infants and 118 (67-179) $\mu \mathrm{g} / \mathrm{L}$ in mothers. Median household SIC was 44 (27-63) ppm. Household SIC and maternal urinary sodium excretion predicted UIC of lactating mothers. Median BMIC was 179 (126-269) $\mu \mathrm{g} / \mathrm{L}$. Age of infants, SIC, and maternal UIC predicted BMIC. In turn, infant age and BMIC predicted UIC of infants. Forty-two percent of SIC values were within the South African recommended salt iodine fortification level at production of $35-65 \mathrm{ppm}$, whilst $21 \%$ of SIC were $>65 \mathrm{ppm}$. Thyroid-stimulating hormone, total thyroxine, and thyroglobulin concentrations in the dried whole blood spot specimens from the infants were $1.3(0.8-1.9) \mathrm{mU} / \mathrm{L}, 128 \pm 33 \mathrm{mmol} / \mathrm{L}$, and 77.1 (56.3-105.7) $\mu \mathrm{g} / \mathrm{L}$, respectively, and did not correlate with infant UIC or BMIC.

Conclusion: Our results suggest that the salt fortification program in South Africa provides adequate iodine to lactating women and indirectly to their infants via breast milk. However, monitoring of salt iodine content of the mandatory salt iodization program in South Africa is important to avoid over-iodization of salt.

Keywords: Breast-milk iodine concentration, urinary iodine concentration, salt iodine concentration, lactating women, infants, thyroid hormones

Conflict of interest: None declared

Received: 10.12 .2015

Accepted: 22.05 .2016

Address for Correspondence

Jennifer Osei PhD, North-West University, Centre of Excellence for Nutrition, Potchefstroom, South Africa

Phone: +27182994011 E-mail: akosyosei@gmail.com

This study was presented in "Developmental Origins of Health and Disease Congress 2015"

OJournal of Clinical Research in Pediatric Endocrinology, Published by Galenos Publishing. 


\section{Introduction}

Dietary iodine is an essential substrate for thyroid hormone [thyroxine $\left(T_{4}\right)$ and triiodothyronine $\left(T_{3}\right)$ ] synthesis and is as such required for normal brain development, growth, and metabolism (1). Both low and high iodine intake can lead to thyroid dysfunction (2). Infants may be particularly vulnerable to iodine deficiency and iodine excess as the fetal and newborn thyroid has limited iodine stores and adapts poorly to high intakes $(3,4,5)$. Acute iodine excess from for example maternal iodine supplements and iodine containing skin disinfectants may cause hypothyroidism in newborns $(6,7)$. Recent data indicate that older infants may be able to adapt to high iodine intakes and maintain their euthyroid state (8). However, little is known about the effects of habitual high iodine intake on thyroid function in breastfed infants.

Programs of universal salt iodization have made remarkable progress in improving iodine status worldwide, but in a handful of countries, salt iodine fortification is poorly monitored and the iodine intake is excessive $(1,5)$.

In South Africa, in order to achieve a level of $30 \mathrm{ppm}$ at retail and $15 \mathrm{ppm}$ in households, iodization of table salt at a concentration of 35-65 ppm at the point of production was revised in 2006/2007 $(9,10)$. The legislation does not involve fortification of agricultural salt or salt for processed foods. The introduction of universal salt iodization remarkably improved the iodine status of school children and of women of reproductive age. The 2005 South African Food-Based National Food Consumption Survey (NFCS-FB-I) reported a median urinary iodine concentration (UIC) in South African school children and women of reproductive age of $215 \mu \mathrm{g} / \mathrm{L}$ and $177 \mu \mathrm{g} / \mathrm{L}$, respectively, indicating overall adequate iodine intake (11). However, more recent data point gaps in iodine nutrition of South Africans, as more than a third of the population still lacks access to adequately iodized salt $(9,12)$. Furthermore, no data exist on iodine status in lactating women and infants.

The iodine requirements as recommended by World Health Organization (WHO) increase to $250 \mu \mathrm{g}$ during lactation: additional to the recommended daily intake of $150 \mu \mathrm{g}$ iodine for women of reproductive age, lactating women should consume $100 \mu \mathrm{g} /$ day extra in order to cover the additional iodine need of their breastfed infants (10). Breastfed infants depend on iodine from breast milk for the synthesis of thyroid hormones and to build up intra-thyroidal iodine stores $(13,14)$. Breast-milk iodine concentrations (BMIC) are determined by the maternal iodine intake; population medians have been shown to range from 9-32 $\mu \mathrm{g} / \mathrm{L}$ in iodine deficient goitrous areas to $146 \mu \mathrm{g} / \mathrm{L}$ in iodine sufficient Chinese women $(15,16)$. The WHO recommends a dietary iodine intake of $90 \mu \mathrm{g} / \mathrm{day}$ for infants aged 0-6 months (10).

Population iodine status is assessed by UIC, as $90 \%$ of ingested iodine is excreted through the renal system and median spot UIC directly reflects recent dietary iodine intake
$(1,10)$. In lactating women and in children $<2$ years, a median UIC $<100 \mu \mathrm{g} / \mathrm{L}$ indicates insufficient iodine intake (10).

Measurement of serum or dried blood spot thyroglobulin (Tg) can be an additional useful biomarker of iodine status to accompany UIC measurements. Zimmermann et al, (17) showed that $\mathrm{Tg}$ is a sensitive marker for both low and high iodine intakes in school-aged children. $\mathrm{Tg}$ is also a sensitive indicator for iodine deficiency in adults $(18,19)$.

Despite the importance of adequate iodine status and thyroid health in lactating women and their breastfed infants, to date, no data exist on BMIC or iodine status of infants and lactating South African women. This study therefore assessed iodine status, BMIC, and thyroid function of breastfed infants and their lactating mothers living in a township located in the North-West Province of South Africa and further explored potential predictors of UIC, thyroid function, and BMIC.

\section{Methods}

\section{Participants}

This study included a convenient sample of 100 apparently healthy infants aged 2-4 months and their lactating mothers residing in two peri-urban settlements (Ikageng and Promosa) on the fringes of Potchefstroom in the Kenneth Kaunda District municipal area, in the North West Province of South Africa. The majority of residents in these townships are of Black African descent, the socio-economic status is low, and unemployment is high. Recruitment of mother-infant pairs was done at local health clinics in Ikageng and Promosa. Infants included in the study were: 1) generally healthy; 2) singletons; 3) had no history of thyroid disease; 4) currently being breastfed; and 5) not using any iodine containing supplements. Mothers included in the study were: 1) generally healthy; 2) had no history of thyroid disease; 3) currently breastfeeding; and 4) not using any iodinecontaining supplements.

This study was conducted according to the guidelines laid down in the Declaration of Helsinki, and all procedures involving human subjects were approved by the Health Research Ethics Committee of the North-West University (NWU-00016-13-A1). Permission was also granted from the Provincial and District Health Departments in the North West Province to recruit mother-infant pairs for this study at local health clinics. The study protocol was fully explained by a trained study assistant fluent in the local language (Setswana or Afrikaans) and written informed consent was obtained from participating women.

\section{Data Collection}

The study design was cross-sectional. Lactating mothers and their infants were invited to the metabolic clinic at the North-West University, South Africa, where the study procedures were conducted between 08:00 am and 12:00 am. Mothers were asked to bring samples of salt $(10 \mathrm{~g})$ 
and water $(10 \mathrm{~mL})$ from their homes. Upon arrival, the study protocol was fully explained to the mothers in their home language (Setswana or Afrikaans) and they signed informed consent. A detailed questionnaire was used to collect information on socio-economic characteristics, use of iodized salt, consumption of iodine-containing foods, use of iodinecontaining supplements (currently and during pregnancy), and breastfeeding practices. Breastfeeding practices were divided into three categories, namely: 1) Exclusive breastfeeding; 2) Predominantly breastfeeding; 3) Partial breastfeeding (20).

Height and weight of mothers and weight, length, and head circumference of infants were measured using standard anthropometric techniques (21). For the measurements, mothers removed their shoes, emptied their pockets, and wore minimal clothing. Height measurements were done using a rigid stadiometer and recorded to the nearest $0.5 \mathrm{~cm}$. Weights of the women were measured on a high capacity electronic flat scale (seca 813; Germany) and recorded to the nearest 0.1 $\mathrm{kg}$. Measurements of infants were done using an infant scale (seca 334; Germany) to the nearest $2 \mathrm{~g}$ with no clothing or nappy. To measure length, infants wore only their nappy, and measurements were taken to the nearest centimeter on a ShorrBoard portable height-length measuring board with autolock sliding foot piece (Weigh and measure, LLC; USA). Head circumference was also measured using a head circumference measuring tape for infants (seca 212; Germany) to the nearest centimeter. Body mass index-for-age z-scores (BAZ) were calculated using the WHO (2006) growth standards. Wasting was defined as $B A Z<-2$, normal weight as $B A Z \geq-2$ and $\leq 2$, risk for overweight as $B A Z>1$, and overweight as $B A Z>2$ (22).

A standard breakfast was served to the mothers at arrival at the metabolic clinic and before collection of biological samples. Spot urine samples $(5 \mathrm{~mL})$ were obtained from the mothers (within a maximum interval of 30 minutes after breakfast consumption), aliquoted, and stored at -80 OC until analysis. Breast milk samples ( $5 \mathrm{~mL}$ of foremilk) were obtained by manual expression. To obtain foremilk, mothers were asked to express milk from the breast that was not used at the last feed. The baby was then allowed to suckle the breast until fully satisfied. Breast milk samples were aliquoted and stored at $-20{ }^{\circ} \mathrm{C}$ until analysis. Spot urine samples were collected from infants using a urine collection pad (SteriSets Uricol Set), aliquoted, and stored at $-80{ }^{\circ} \mathrm{C}$ until analysis. Whole blood obtained via venipuncture or foot prick was spotted onto filter paper (Whatman 903; GE Healthcare) and allowed to dry at room temperature for 24 hours. They were then stored at -20 OC in sealed low-density polyethylene bags containing desiccant packets until analysis of thyroid hormones.

\section{Laboratory Analysis}

UIC in spot urine samples from infants and mothers was measured in duplicate at the North-West University in Potchefstroom using the Pino modification of the Sandell-
Kolthoff reaction with spectrophotometric detection $(10,23)$. The laboratory successfully participates in the Program to Ensure the Quality of Urinary lodine Procedures (EQUIP, U.S. Centers for Disease Control and Prevention, Atlanta GA, USA) (24). lodine in spot urine samples from infants and lactating mothers were expressed as median concentrations $(\mu \mathrm{g} / \mathrm{L})$. A median UIC greater than $100 \mu \mathrm{g} / \mathrm{L}$ was considered to indicate adequate iodine intake in lactating women and infants (10).

In lactating mothers, we additionally determined the iodine:creatinine ratio ( $\mu \mathrm{g}$ iodine/g creatinine) to reduce the intra-individual variation in daily urine volume and also to adjust for fluid intake $(25,26)$. Urinary creatinine and sodium concentrations in spot urine from mothers were analyzed using the UniCel ${ }^{\circledR}$ DxC800 System (Beckman Coulter) at a commercial pathological laboratory (Ampath Johannesburg).

BMIC was analyzed at the Laboratory of Human Nutrition of ETH Zurich, Switzerland (27). lodine was extracted from the samples using a modified tetramethylammonium hydroxide (TMAH) extraction procedure $(28,29)$. The iodine content in filtered TMAH extracts was measured using a multicollector inductively coupled plasma mass spectrometer (MC-ICPMS [Finnigan NEPTUNE, Thermo Scientific ${ }^{T M}$ Waltham, MA, USA]). Quantification was done using isotope dilution analysis with 129I (SRM 4949C, National Institute of Standards and Technology [NIST], Gaithersburg, MD, USA). Tellurium (AppliChem, Darmstadt, Germany) was used for mass bias correction of the measured $127 \mid / 129$ | intensity ratio according to Russell's law. The iodine concentrations of the milk samples were calculated using the dilution factors applied to each milk sample. Standard reference material (SRM 1549a, Whole Milk Powder, NIST, Gaithersburg, MD, USA) was analyzed as external control with each ICP-MS run (30). The method was recently validated at the Human Nutrition Laboratory of ETH Zurich, Switzerland. The mean [ \pm standard deviation (SD)] iodine content for the NIST SRM1549a reference material was $3502( \pm 89) n g / g(n=16)$, well within the certified acceptable range $(3040-3640 \mathrm{ng} / \mathrm{g})$. The total-assay variability of the method is $2.6 \%$. The within-assay variability is $1.1 \%$ and the between-assay variability is $1.3 \%$. The limit of detection of the method is $0.26 \mathrm{ng} / \mathrm{g}$.

Dried whole blood spots were analyzed for thyroidstimulating hormone (TSH) (DELFIA NeoTSH kit, PerkinElmer Life Sciences, Turku, Finland) and total thyroxine $\left(\mathrm{TT}_{4}\right)$ (Delfia Neonatal $T_{4}$ kit, PerkinElmer Life Sciences, Turku, Finland) using automated fluoroimmunoassay (31). Analysis of dried blood spots-Tg (DBS-Tg) was done by a new sandwich enzymelinked immunosorbent assay that was recently developed and validated at the Human Nutrition Laboratory of ETH Zurich, Switzerland (32). Serum control samples (Liquicheck Tumor Marker Control, Bio-Rad, Hercules, CA, USA) were used as standards for the DBS-Tg assay. Normal reference ranges for TSH and $\mathrm{T}_{4}$ as supplied by the manufacturer were as follows: $\mathrm{TSH}$ of 0.1-4.5 mU/L and 0.1-3.7 $\mathrm{mU} / \mathrm{L}$ for 60-155-day-old 
infants and for subjects 1-99 years of age, respectively; $\Pi_{4}$ of 80-165 nmol/L and 65-165 nmol/L for 60-155-day-old infants and for subjects 1-99 years of age, respectively. Normal range reference values for DBS-Tg are only available for school-age children $(4-40 \mu \mathrm{g} / \mathrm{L})$ but not for young children and infants $(33,34)$.

Salt iodine concentrations (SIC) and water iodine concentrations $(\mathrm{WIC})$ were determined by using the Pino modification of the Sandell-Kolthoff reaction with spectrophotometric detection (23). Household SIC was expressed as median and classified into three categories, according to ranges in ppm based on the 2006/2007 South African mandatory fortification level for table salt at the point of production (9). Salt samples were considered inadequately, adequately, and over-iodized when SIC was $<35$ ppm, 35-65 ppm, and >65 ppm, respectively. Household SIC were also classified into the three fortification categories indicating inadequately (SIC <15 ppm), adequately (SIC 15-40 ppm), or excessively (SIC $>40 \mathrm{ppm}$ ) iodized salt at household level as recommended by WHO (35).

Data on the intake of potentially iodine-rich foods in lactating mothers were collected using an unquantified food frequency questionnaire and presented as the number (\%) of mothers who consumed specific iodine-rich foods.

\section{Statistical Analysis}

All data processing and analysis were done using IBM SPSS statistics version 20. Data were checked for normality using Q-O plots and the Shapiro-Wilk test. Normally distributed data were presented as mean \pm SD. Non-normally distributed data were presented as median (25th-75th percentiles) values. For between-group comparisons, the Mann-Whitney U or KruskalWallis tests were used for non-parametric data. Spearman correlations were performed to determine associations between variables. Multiple linear regression analyses were used to explore whether household SIC, salt intake of mothers (urinary sodium excretion), UIC of mothers (only for BMIC and UIC of infants as dependent variable), age of mothers and infants, and BMIC (only for UIC of mothers and infants as dependent variables) were predictors of BMIC and UIC in lactating mothers and breastfed infants. Other dietary and maternal factors [e.g. mode of breastfeeding and delivery, smoking habits, human immunodeficiency virus (HIV) status] were also tested using a stepwise procedure, but none of those were significant predictors of BMIC or UIC of mothers and infants and were therefore not included in the final regression models. Non-parametric dependent variables were transformed prior to analysis. Furthermore, we examined the odds ratios $(\mathrm{OR})$ for infants to have abnormal thyroid hormone concentrations with excessive or inadequate iodine intake using binary logistic regression analyses, adjusting for age of mothers and infants, as well as HIV status of mothers. A p-value $<0.05$ was considered significant.

\section{Results}

One hundred mother-infant pairs participated in the study. Characteristics of the infants and mothers are shown in Table 1. Infants were aged 3-4 months (mean \pm SD: $3.0 \pm 1.1$ ); 54 were females and 46 were males. Of all the infants, $67 \%$ were exclusively breastfed, whilst $9 \%$ and $24 \%$ were predominantly and partially breastfed, respectively.

The median (25th-75th percentiles) UIC of infants $(n=92)$ was 373 (202-627) $\mu \mathrm{g} / \mathrm{L}$ (Table 2). The median UIC of mothers was $118(67-179) \mu \mathrm{g} / \mathrm{L}$ and the iodine:creatinine ratio was 126 (86-207) $\mu \mathrm{g} / \mathrm{g}$. Figure 1 illustrates the frequency distribution of infant and maternal spot UIC, and BMIC. Thirty-nine percent of mothers had UIC $<100 \mu \mathrm{g} / \mathrm{L}$, whereas, only $4 \%$ of infants had UIC $<100 \mu \mathrm{g} / \mathrm{L}$. Fifty-three per cent of infants had a UIC $>300$ $\mu \mathrm{g} / \mathrm{L}$ and $26.1 \%>600 \mu \mathrm{g} / \mathrm{L}$. UIC of mothers were positively correlated with the UIC of infants $\left(r_{s}=0.425, p<0.001\right)$ (Figure 2A). The UIC of both infants and mothers were positively correlated with BMIC (infants: $r_{s}=0.552, p<0.001$; mothers: $r_{s}=0.593, p<0.001$ ) (Figure 2B, 2C). Infants of obese mothers had higher UIC [495.3 (141.8-1060.9) $\mu \mathrm{g} / \mathrm{L} ; \quad p=0.04]$ than infants of mothers that were normal weight $(n=39)$. We found no other association of UIC in infants and mothers with participant characteristics and frequency of iodine-containing foods consumed by mothers. Generally, cow's milk was consumed either every day or sometimes by $82 \%$ of mothers. Whilst 60\% consumed fish sometimes, $69 \%$ consumed meat always (Table 3).

Median BMIC was 179 (126-269) $\mu \mathrm{g} / \mathrm{L}$. Median SIC ( $\mathrm{n}=85)$ was 44 (27-63) ppm. The majority of women (90\%) used adequately iodized salt in the household ( $\geq 15 \mathrm{ppm}$ ) as defined by $\mathrm{WHO}, 42 \%$ consumed salt that was within the South African recommended salt iodine fortification level at production (35-65 ppm), whilst $21 \%$ of households consumed salt that was iodized above $65 \mathrm{ppm}$. lodine in water collected from the different households was below detection limit $(<10 \mu \mathrm{g} / \mathrm{L})$.

The UICs of infants and their mothers were positively correlated with household SIC (infants: $r_{S}=0.341, p<0.001$; mother: $\left.r_{s}=0.252, p<0.001\right)$. The median UIC of mothers from households with SIC above 65 ppm [185 (117-411) $\mu \mathrm{g} / \mathrm{L}]$ was higher than that of mothers from households with iodized salt containing 35-65 ppm [105 (68-163) $\mu \mathrm{g} / \mathrm{L} ; \mathrm{p}=0.024]$ and that of mothers from households with SIC below 35 ppm [117 (62-136) $\mu \mathrm{g} / \mathrm{L} ; \mathrm{p}=0.004]$. Likewise, the median UIC of infants from households with SIC above 65 ppm [719 (478-911) $\mu \mathrm{g} / \mathrm{L}]$ was higher than of infants from households with iodized salt at 35-65 ppm [346 (194-530) $\mu \mathrm{g} / \mathrm{L} ; \mathrm{p}=0.006$ ] and with SIC below 35 ppm [250 (177-411) $\mu \mathrm{g} / \mathrm{L} ; \mathrm{p}<0.001]$.

Using multiple linear regression analysis, household SIC and maternal urinary sodium excretion significantly predicted UIC of lactating mothers (Table 4). Household SIC, maternal UIC, and age of infants significantly predicted BMIC. In turn, BMIC as well as infant age significantly predicted UIC in infants. 
Table 1. Characteristics of breastfed infants and their lactating mothers

\begin{tabular}{|c|c|c|c|}
\hline & $\%$ & Mean & $\begin{array}{l}\text { Standard } \\
\text { deviation }\end{array}$ \\
\hline \multicolumn{4}{|l|}{ Infants $(n=100)$} \\
\hline Males (\%) & 46 & & \\
\hline Females (\%) & 54 & & \\
\hline Age (months) & & 3.0 & 1.1 \\
\hline Length $(\mathrm{cm})$ & & 58.3 & 3.4 \\
\hline Weight (kg) & & 5.7 & 1.0 \\
\hline \multicolumn{4}{|l|}{ BAZ (\%) } \\
\hline Wasted (BAZ <-2) & 3 & & \\
\hline Normal $(-2 \geq B A Z \leq 1)$ & 80 & & \\
\hline Risk for overweight $(B A Z>1)$ & 11 & & \\
\hline Overweight (BAZ >2) & 6 & & \\
\hline \multicolumn{4}{|l|}{ Mothers $(n=100)$} \\
\hline Age (years) & & 27.7 & 6.8 \\
\hline Number of children & & 2.2 & 1.2 \\
\hline HIV-positive (\%) & 22 & & \\
\hline Smoking now (\%) & 10 & & \\
\hline Smoking before pregnancy (\%) & 8 & & \\
\hline \multicolumn{4}{|l|}{ Education (\%) } \\
\hline Primary & 5 & & \\
\hline Secondary & 90 & & \\
\hline Tertiary & 4 & & \\
\hline Other & 1 & & \\
\hline Employed (\%) & 11 & & \\
\hline \multicolumn{4}{|l|}{ Mode of delivery (\%) } \\
\hline Vaginal delivery & 79 & & \\
\hline Caesarean & 21 & & \\
\hline Height (m) & & 1.57 & 0.05 \\
\hline Weight (kg) & & 66.5 & 14.7 \\
\hline \multicolumn{4}{|l|}{ BMI (\%) } \\
\hline Underweight (BMI <18.5) & 3 & & \\
\hline Normal weight (BMI 18.5-24.9) & 39 & & \\
\hline Overweight (BMI 25.0-29.9) & 31 & & \\
\hline Obese (BMI $\geq 30$ ) & 27 & & \\
\hline \multicolumn{4}{|l|}{ Breastfeeding practice (\%) } \\
\hline Exclusive & 67 & & \\
\hline Predominant & 9 & & \\
\hline Partial & 24 & & \\
\hline
\end{tabular}

Thyroid hormone concentrations in lactating mothers and their infants are shown in Table 2. Infant $\mathrm{TSH}_{1} \mathrm{TT}_{4}$, and $\mathrm{Tg}$ concentrations were $1.3(0.8-1.9) \mathrm{mU} / \mathrm{L}, 128 \pm 33$ $\mathrm{mmol} / \mathrm{L}$, and 77.1 (56.3-105.7) $\mu \mathrm{g} / \mathrm{L}$, respectively. Mother $\mathrm{TSH}_{1} \mathrm{TT}_{4}$, and $\mathrm{Tg}$ concentrations were 0.8 (0.6-1.0) $\mathrm{mU} / \mathrm{L}$, $69.6 \pm 15.9 \mathrm{mmol} / \mathrm{L}$, and 22.2 (14.4-30.7) $\mu \mathrm{g} / \mathrm{L}$, respectively. We found that $99 \%$ of infants had TSH concentrations within the normal range. No associations of UIC were found with $\mathrm{Tg}, \mathrm{TSH}$, and thyroid hormone concentrations in infants or mothers. However, median TSH concentrations were significantly higher in HIV-positive $[0.95(0.0-1.7) \mathrm{mU} / \mathrm{L}]$ than HIV-negative $[0.7(0.0-2.2) \mathrm{mU} / \mathrm{L}]$ mothers $(p=0.021)$. Further, maternal $\mathrm{TT}_{4}$ concentrations were associated with $\mathrm{TT}_{4}$ concentrations of their infants $(r=0.236, p=0.020)$. $\mathrm{TT}_{4}$ concentrations were significantly lower in HIV-positive $(61.0 \pm 15.3 \mathrm{nmol} / \mathrm{L})$ than HIV-negative $(72.1 \pm 15.3 \mathrm{nmol} / \mathrm{L})$ mothers $(p=0.004)$. In turn, the odds for having low $\mathrm{TT}_{4}$ concentrations were significantly higher in HIV-positive $\left(\mathrm{TT}_{4}<65 \mathrm{nmol} / \mathrm{L}=63 \%\right)$ than HIV-negative $\left(\mathrm{TT}_{4}<65 \mathrm{nmol} /\right.$ $L=37 \%$ ) mothers (OR=2.95, 95\% confidence interval: 1.117.90). We did not observe any significant differences in $\mathrm{Tg}$ concentrations by HIV status. Furthermore, the thyroid hormone status of the infants did not differ with regard to maternal HIV status.

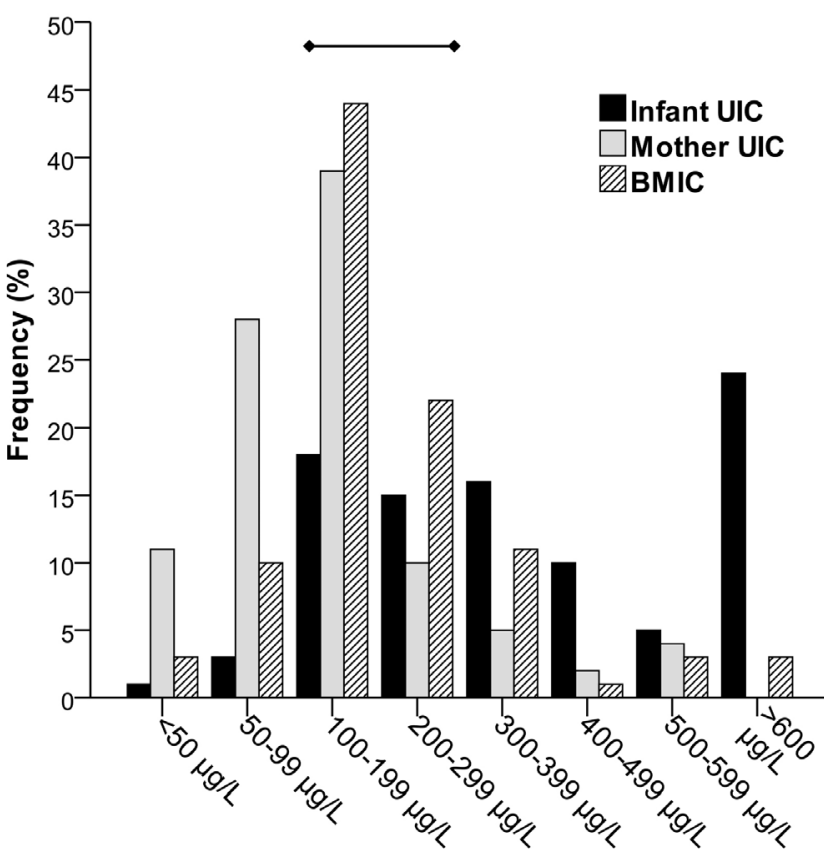

Figure 1. Frequency distribution of spot urinary iodine concentrations of lactating mothers $(n=100)$ and their breastfed infants $(n=92)$, and breastmilk iodine concentrations in $\mu \mathrm{g} / \mathrm{L}$. The urinary iodine concentrations range indicating sufficient iodine intake in lactating women and infants is highlighted

UIC: urinary iodine concentration, BMIC: breast-milk iodine concentration 


\section{Discussion}

To our knowledge, this is the first study to report iodine status, BMIC, and thyroid function of breastfed infants and lactating mothers in South Africa. Our findings suggest adequate iodine status in both lactating women and their breastfed infants in this convenience sample. Based on a BMIC of $179 \mu \mathrm{g} / \mathrm{L}$ and a breast-milk consumption of $0.78 \mathrm{~L}$ at 3 months (36), infants consumed $140 \mu \mathrm{g}$ iodine/day, well above the recommended daily iodine intake of $90 \mu \mathrm{g}$ and $110 \mu \mathrm{g}$ for infants below 6 months of age by WHO and the Institute of Medicine (IOM), respectively $(10,36)$. WHO applies the threshold of $\geq 100 \mu \mathrm{g} / \mathrm{L}$ for the median UIC to determine iodine sufficiency in children less than 2 years of age. This cut-off sharply disagrees with the intake recommendations from both $\mathrm{WHO}$ and IOM. By assuming a urine volume in infants of approximately $500 \mathrm{~mL} /$ day and $90 \%$ bioavailability and excretion $(10,36)$, the UIC corresponding to the recommended dietary iodine intake of $90-110 \mu \mathrm{g} /$ day would be in the range of $160-240 \mu \mathrm{g} / \mathrm{L}$. Although the median UIC in the infants in our study is more than 3 times higher than the WHO UIC threshold, it should be noted that no range for median UIC reflecting optimal iodine nutrition during infancy has been defined. Considering the small urine volume in infants, a wide UIC range is expected. Previous studies in

\begin{tabular}{|c|c|c|c|c|c|c|}
\hline \multicolumn{3}{|c|}{ Infants } & n & Median & $25^{\text {th }}$ percentile & 75th percentile \\
\hline & \multicolumn{2}{|c|}{ Urinary iodine concentration ( $\mu \mathrm{g} / \mathrm{L})$} & 92 & 373 & 202.0 & 627.0 \\
\hline & \multicolumn{2}{|c|}{ Estimated $24 \mathrm{~h}$ iodine intake from breast milk $(\mu / \text { day })^{2}$} & 97 & 140 & 97.9 & 209.4 \\
\hline & \multicolumn{2}{|c|}{ TSH (mU/L) } & 96 & 1 & 0.8 & 1.9 \\
\hline & & $\mathrm{TSH}>4.5 \mathrm{mU} / \mathrm{L}(\mathrm{n}[\%])$ & & $1[1]$ & & \\
\hline & \multicolumn{2}{|c|}{$\mathrm{T} 4$ (mmol/L) } & 97 & $128.0(32.8)^{*}$ & & \\
\hline & & $\mathrm{T}_{4}<80 \mathrm{nmol} / \mathrm{L}(\mathrm{n}[\%])$ & & $5[5.2]$ & & \\
\hline & & $80 \geq \mathrm{T}_{4} \leq 165 \mathrm{nmol} / \mathrm{L}(\mathrm{n}[\%])$ & & $81[83.5]$ & & \\
\hline & & $\mathrm{T}_{4}>165 \mathrm{nmol} / \mathrm{L}(\mathrm{n}[\%])$ & & 11 [11.3] & & \\
\hline & \multicolumn{2}{|c|}{$\operatorname{Tg}(\mu \mathrm{g} / \mathrm{L})(\mathrm{n}=66)^{1}$} & & 77 & 56.3 & 105.7 \\
\hline & \multicolumn{2}{|c|}{ Subclinical hypothyroidism (n [\%]) } & & $0[0]$ & & \\
\hline & \multicolumn{2}{|c|}{ Overt hypothyroidism (n [\%]) } & & $0[0]$ & & \\
\hline & \multicolumn{2}{|c|}{ Hypothyroxinemia (n [\%]) } & & $5[5.2]$ & & \\
\hline \multicolumn{7}{|c|}{ Mothers } \\
\hline & \multicolumn{2}{|c|}{ Urinary iodine concentration ( $\mu \mathrm{g} / \mathrm{L})$} & 100 & 118 & 67 & 179 \\
\hline & \multicolumn{2}{|c|}{ lodine-creatinine ratio $(\mu \mathrm{g} / \mathrm{g})$} & 100 & 126 & 86 & 207 \\
\hline & \multicolumn{2}{|c|}{ Breast-milk iodine concentration ( $\mu \mathrm{g} / \mathrm{L})$} & 100 & 179 & 126 & 269 \\
\hline & \multicolumn{2}{|c|}{ Urinary sodium excretion in spot samples (mmol/g creatinine) } & 88 & 154 & 99 & 220 \\
\hline & \multicolumn{2}{|c|}{ TSH (mU/L) } & 100 & 0.8 & 0.6 & 1.0 \\
\hline & & $\mathrm{TSH}>3.7 \mathrm{mU} / \mathrm{L}(\mathrm{n}[\%])$ & & $0[0]$ & & \\
\hline & \multicolumn{2}{|c|}{$\mathrm{T}_{4}(\mathrm{mmol} / \mathrm{L})$} & 100 & $69.6(15.9)^{*}$ & & \\
\hline & & $\mathrm{T}_{4}<65 \mathrm{nmol} / \mathrm{L}(\mathrm{n}[\%])$ & & $43[57]$ & & \\
\hline & \multicolumn{2}{|l|}{$\operatorname{Tg}(\mu \mathrm{g} / \mathrm{L})$} & 96 & $22.2(14.4-30.7)$ & 14.4 & 30.7 \\
\hline & & $\mathrm{Tg}>40 \mu \mathrm{g} / \mathrm{L}(\mathrm{n}[\%])$ & & $16[17]$ & & \\
\hline & \multicolumn{2}{|c|}{ Subclinical hypothyroidism (\%) } & 100 & 0 & & \\
\hline & \multicolumn{2}{|c|}{ Overt hypothyroidism (\%) } & 100 & 0 & & \\
\hline & \multicolumn{2}{|c|}{ Hypothyroxinemia (\%) } & 100 & 43 & & \\
\hline \multicolumn{7}{|c|}{$\begin{array}{l}\mathrm{T}_{4} \text { : thyroxine, TSH: thyroid-stimulating hormone, Tg: thyroglobulin. } \\
\text { Subclinical hypothyroidism defined as elevated TSH (relative to age-specific cutoffs) and normal } \mathrm{T}_{4} \text {; overt hypothyroidism defined as elevated TSH (relative to age-specific cutoff) and } \\
{ }^{l} \text { low } \mathrm{T}_{4} \text { (relative to age-specific cutoffs); and hypothyroxinemia defined as } \mathrm{T}_{4} \text { less than age-specific cutoff and normal TSH. } \\
{ }^{1} \text { Eight values were above measuring range of } 150 \mu \mathrm{g} / \mathrm{L} \text {. } \\
{ }^{2} 24 \mathrm{~h} \text { iodine intake from breast milk was estimated on the basis of the measured breast-milk iodine concentrations and assuming that the mean breast milk intake in infants } 0-6 \text { months } \\
\text { of age is } 0.78 \mathrm{~L} / \text { day ( } 36 \text { ). } \\
{ }^{*} \text { Normally distributed data presented as mean (standard deviation) }\end{array}$} \\
\hline
\end{tabular}


Niger and Algeria also reported high median UICs $(220 \mu \mathrm{g} / \mathrm{L}$ and $728 \mu \mathrm{g} / \mathrm{L}$, respectively) in breastfed infants $(33,37,38)$. Lower median UICs were observed in exclusively breastfed infants from the Boston area in the U.S. (204 $\mu \mathrm{g} / \mathrm{L})$ and Switzerland (82

A
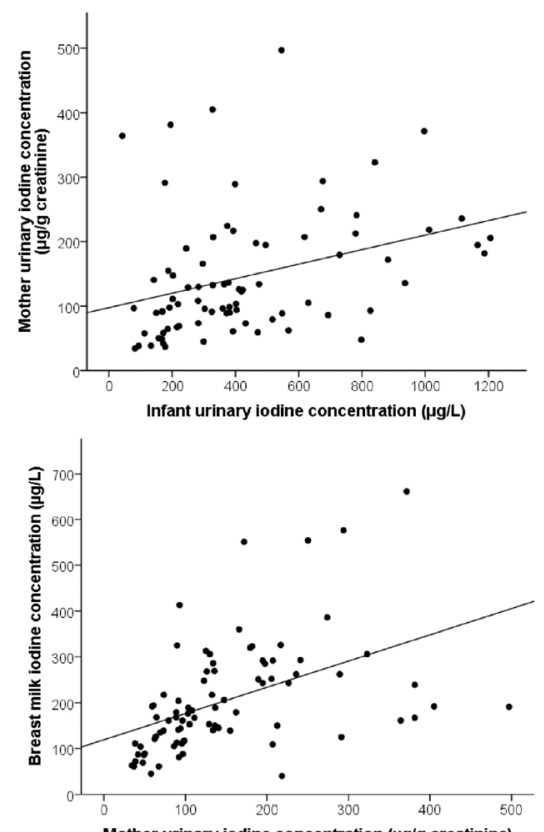

C

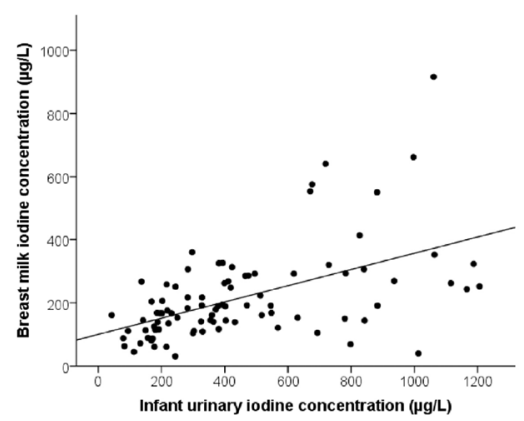

Figure 2. Scatter plots indicating the Spearman correlations between (A) urinary iodine concentrations of South African lactating mothers and their breastfed infants (Spearman correlations: $r_{s}=0.425$ and $p<0.001$ ); (B) Urinary iodine concentrations of lactating mothers and breast-milk iodine concentrations $\left(r_{s}=0.593\right.$ and $\left.p<0.001\right)$; (C) Urinary iodine concentrations of infants and breast-milk iodine concentrations $\left(r_{s}=0.552\right.$ and $\left.p<0.001\right)$ $\mu \mathrm{g} / \mathrm{L})$ which are both considered iodine-sufficient populations $(39,40)$. The scientific basis for the dietary iodine requirements during infancy is weak. The IOM intake recommendation is an Adequate Intake (Al) because there were insufficient data to establish an Estimated Average Requirement (EAR) for this age group and no upper intake level has been defined $(10,36)$. Work is on-going to add data to this knowledge gap (ClinicalTrials.gov: Project NCT02045784).

The median $\mathrm{Tg}$ concentrations of $77.1 \mu \mathrm{g} / \mathrm{L}$ is six times higher than reported in iodine-sufficient school-aged children (17). Pediatric reference ranges for serum-Tg assays indicate physiologically elevated $\mathrm{Tg}$ concentrations during the first two years of life $(41,42)$. The Tg concentrations gradually decline with age. Infant reference values are lacking for DBS-Tg as well as data on DBS-Tg in iodine-sufficient breastfed infant populations. However, the magnitude of the elevated DBS$\mathrm{Tg}$ concentration in infants in our study compared to median DBS-Tg concentration observed in iodine-sufficient school children suggests that Tg production may increase in response to a marginally high iodine intake in infants. However, none of the infants had subclinical hypothyroidism, and we found no associations of infant UIC with $\mathrm{Tg}$, TSH, and $\mathrm{T}_{4}$ concentrations, indicating a possible adaptation of the thyroid gland.

Based on median UIC, lactating women in the present study have adequate iodine status. The iodine intake in the mothers is estimated to $320 \mu \mathrm{g} / \mathrm{day} ; 140 \mu \mathrm{g}$ iodine is excreted in the breast milk and $180 \mu \mathrm{g}$ in the urine lassuming a urine volume of 1.5 liters/day). All women have normal TSH concentrations. The high prevalence of hypothyroxinemia should be interpreted with caution; we applied the $\mathrm{TT}_{4}$ thresholds defined for women of reproductive age in the absence of normal reference ranges for maternal $T_{4}$ in breastfeeding women. Cross-sectional data suggest lower $\Pi_{4}$ concentrations during early lactation $(43,44)$. In addition, we observed higher TSH and lower $\mathrm{TT}_{4}$ concentration in HIVpositive women than in HIV-negative women. Abnormalities in thyroid function of HIV patients have been previously described $(45,46)$. Most HIV-positive mothers in our study reported to be on the highly active antiretroviral therapy (HAART). Increased prevalence of sub-clinical hypothyroidism is known to occur in HIV treated patients, especially those on HAART $(47,48)$. Madeddu et al (49) emphasized the need to sequentially check thyroid function in HIV patients on HAART after they

\begin{tabular}{|c|c|c|c|c|c|}
\hline \multirow[t]{2}{*}{ General frequency of consumption (\%) } & \multicolumn{5}{|l|}{ Foods } \\
\hline & Cow's milk $(n=100)$ & Fish $(n=99)$ & Seafood $(n=100)$ & Eggs $(n=100)$ & Meat $(n=99)$ \\
\hline Never & 4.0 & 16.2 & 89.0 & 7.0 & 1.0 \\
\hline Rarely & 9.0 & 20.2 & 0 & 32.0 & 1.0 \\
\hline Sometimes & 52.0 & 60.6 & 11.0 & 46.0 & 10.1 \\
\hline Often & 5.0 & 3.0 & 0 & 6.0 & 18.2 \\
\hline Always & 30.0 & 0 & 0 & 9.0 & 69.7 \\
\hline
\end{tabular}


Osei J et al.

lodine Status of Infants and Lactating Women

Table 4. Predictors of breast-milk iodine concentration and urinary iodine concentration in South African lactating mothers and breastfed infants

\begin{tabular}{|c|c|c|c|c|c|c|}
\hline \multirow[b]{2}{*}{ Multiple linear regression } & \multicolumn{2}{|c|}{$\begin{array}{l}\text { UIC ( } \mu \mathrm{g} / \mathrm{g} \text { creatinine) in } \\
\text { mothers }\end{array}$} & \multicolumn{2}{|c|}{ BMIC $(\mu g / L)$} & \multicolumn{2}{|c|}{ UIC $(\mu \mathrm{g} / \mathrm{L})$ in infants } \\
\hline & $\beta$ & $p$ & $\beta$ & p & $\beta$ & $\mathrm{p}$ \\
\hline Salt iodine concentrations $(\mu \mathrm{g} / \mathrm{g})$ & 0.340 & 0.003 & 0.329 & 0.005 & 0.120 & 0.349 \\
\hline Sodium excretion (mmol $\mathrm{Na} / \mathrm{g}$ creatinine) & 0.461 & $<0.001$ & 0.174 & 0.115 & 0.215 & 0.061 \\
\hline Age infant (months) & -0.084 & 0.455 & -0.386 & $<0.001$ & 0.281 & 0.019 \\
\hline Age mother (years) & 0.123 & 0.241 & 0.001 & 0.989 & 0.126 & 0.216 \\
\hline BMIC ( $\mu \mathrm{g} / \mathrm{L})$ & - & - & - & - & 0.522 & $<0.001$ \\
\hline Maternal UIC ( $\mu \mathrm{g} / \mathrm{g}$ creatinine) & - & - & 0.325 & 0.005 & -0.117 & 0.338 \\
\hline Adjusted $R^{2}$ & & 0.243 & & 0.273 & & 0.347 \\
\hline
\end{tabular}

observed elevated TSH levels in these patients as compared to naive patients and controls. This might be particularly crucial in lactating women, considering the positive associations that we observed between $\Pi_{4}$ concentrations in mothers and their infants.

Confirming the influential role of maternal iodine intake on the iodine status of breastfed infants (15), we found maternal UIC to be a predictor for BMIC, which in turn was a predictor for UIC in infants. Most infants included in the present study were exclusively breastfed (67\%), but some mothers reported to occasionally feed their infants with commercial infant formula or other foods (for example, maize meal porridge and commercial infant cereals). We did not observe any differences in infant UIC based on feeding practices. Our findings, however, show that infant age is a strong negative predictor for BMIC, confirming that BMIC may decline within the first six months of lactation (50). Furthermore, discrepancies in literature exist regarding the relationship between maternal and infant UIC. In agreement with our study, various authors have found positive correlations between infant and mother UIC $(38,51,52)$, while others did not $(53,54)$.

Our results indicate that household salt was a major source of iodine for mothers; SIC predicted both BMIC and maternal UIC. The majority (90\%) of women consumed adequately iodized salt (>15 ppm) and our data indicate that the iodized salt coverage in the Potchefstroom area is high and meets the WHO criteria for a successful salt iodization program (10). In 2005 , a national study reported that $77 \%$ of households in South Africa had access to and consumed adequately-iodized salt (9). The median iodine concentration in the household salt was $44 \mathrm{ppm}$, ranging from 0-153 ppm, slightly above the upper level of $40 \mathrm{ppm}$ recommended by WHO (10). lodine is a volatile micronutrient (55) and the iodine fortification level in the South African program (35-65 ppm) has been set to account for possible losses in salt iodine concentrations before salt reaches households. However, our data also show that $21 \%$ of households consumed salt iodized above the upper level of $65 \mathrm{ppm}$. It has been previously documented that poor implementation and insufficient monitoring of universal salt iodization programs worldwide have resulted in inadequate and even excess intakes of iodine in several countries (56). In South Africa, the median iodine concentration in household salt has previously been reported to range from $6 \mathrm{ppm}$ to $42 \mathrm{ppm}$ across all provinces and 30 ppm nationwide (57).

The daily quantity of salt consumed by mothers was beyond the scope of this study and sodium excretion was measured only in spot urine samples, which is not recommended for estimating individual sodium intake. However, $90 \%$ of mothers indicated that they used salt every day for food preparation. The South African population is known to have high salt intakes. The mean salt consumption in the country is 6-12 $\mathrm{g}$ per day per person, which is higher than the WHO recommendation of $\leq 5$ $\mathrm{g}$ of salt ( $<2000 \mathrm{mg}$ sodium) per day per person (58). Currently, policies are being implemented to reduce the salt intake of the general population. Salt intakes as low as $5 \mathrm{~g}$ per day are known to have adequate amounts of iodine, provided the salt is sufficiently iodized (12). Our results indicate that the amount of iodine added to salt by some producers may be to too high and that the compliance with the current legislation (35-65 ppm) is not properly monitored and may therefore lead to over-iodized salt in the market.

In South Africa, fortification of salt is only mandatory for table salt and not for salt used in processed foods. In this study, sodium excretion and household SIC were independent predictors of maternal UIC, indicating that iodized household salt may not have been the sole source for iodine. Thus, the possibility of obtaining iodine from other food sources cannot be over-ruled. For example, there was a reported frequent consumption of cow's milk, and the assessment of various brands of milk available in the local market showed that the iodine content in milk ranged from 116-366 $\mu \mathrm{g} / \mathrm{L}$ (unpublished results). Only few studies have determined whether processed foods in South Africa contain iodized salt. Bread is the major source of dietary salt intake for adults, especially urban black 
dwellers, who are said to obtain $49-54 \%$ of their salt intake from bread and cereal food groups (59). Several manufacturing companies have previously reported to use salt containing substantial amounts of iodine (39-69 ppm), especially for food items that were frequently distributed countrywide (60). These reports are, however, old and it is likely that more food manufacturing companies now use iodized salt.

A limitation of this study is the small sample size. However, the vast amount of data collected in the study provides a complete picture of the iodine status in the studied infants and their mothers. We did not collect data on the use of any iodine containing disinfectants applied for maternal wound disinfection or continuous umbilical care of the infants and acknowledge this limitation (61). Based on information received from clinics and the local hospital, the most commonly used disinfectant in theatre during caesarean delivery is HibiTane ${ }^{\circledR}$ (containing chlorhexidine) in either alcohol or iodine, and water in chlorhexidine is also being used for perineal laceration. lodine is preferably used over alcohol as it is believed to cause less irritation. However, we did not observe any significant difference in UIC between infants born via vaginal delivery or caesarean, therefore ruling out possible contamination from maternal wound disinfectants. Furthermore, in clinics, mothers are mainly advised to use alcohol (surgical spirit) for umbilical care and hence iodine contamination is unlikely.

In conclusion, our results suggest that iodized salt is a major contributor to iodine status in lactating mothers and their infants. The results also show that the salt iodization program in South Africa not only supplies sufficient iodine for children and women of reproductive age, but also for lactating mothers and breastfed infants. However, salt iodine levels appear to be poorly monitored. There is a dire need for on-going monitoring and surveillance of salt fortification at production, to avoid overiodized salt and ensure sustenance of optimal iodine status in vulnerable population groups.

\section{Acknowledgments}

The authors would like to thank all participating mothers and the participating clinics from the Potchefstroom municipality. Our gratitude is also extended to the manager of the metabolic unit, Chrissie Lessing, for making this study possible and ensuring it was well organized. We also thank all the nurses and fieldworkers who assisted with the study procedures. This study was funded by the Human Nutrition Laboratory of ETH Zurich, Switzerland, the Nestle Nutrition Institute Africa and the South African Sugar Association.

\section{Ethics}

Ethics Committee Approval: This study was conducted according to the guidelines laid down in the Declaration of Helsinki and all procedures involving human subjects were approved by the Health Research Ethics Committee (HREC) of the North-West University (NWU-00016-13-A1), Informed Consent: Permission was also granted from the Provincial and District Health Departments in the North West Province to recruit mother-infant pairs for this study at local health clinics.

Peer-review: Externally peer-reviewed.

\section{Authorship Contributions}

Concept: Jennifer Osei, Maria Andersson, Cornelius M. Smuts, Jeannine Baumgartner, Design: Jennifer Osei, Maria Andersson, Cornelius M. Smuts, Jeannine Baumgartner, Data Collection or Processing: Jennifer Osei, Olivia van der Reijden, Susanne Dold, Jeannine Baumgartner, Analysis or Interpretation: Jennifer Osei, Jeannine Baumgartner, Literature Search: Jennifer Osei, Writing: Jennifer Osei.

\section{References}

1. Pearce $E N$, Andersson $M$, Zimmermann MB. Global iodine nutrition: Where do we stand in 2013? Thyroid 2013;23:523-528. Epub 2013 Apr 18

2. Zimmermann $M B$, Boelaert $K$. lodine deficiency and thyroid disorders. Lancet Diabetes Endocrinol 2015;3:286-295. Epub 2015 Jan 13

3. Andersson M, de Benoist B, Rogers L. Epidemiology of iodine deficiency: Salt iodisation and iodine status. Best Pract Res Clin Endocrinol Metab 2010;24:1-11.

4. Theodoropoulos T, Braverman LE, Vagenakis AG. lodide-induced hypothyroidism: a potential hazard during perinatal life. Science 1979;205:502-503.

5. Zimmermann MB. lodine deficiency. Endocr Rev 2009;30:376-408. Epub 2009 May 21

6. Thaker W, Leung AM, Braverman LE, Brown RS, Levine B. lodineinduced hypothyroidism in full-term infants with congenital heart disease: more common than currently appreciated? J Clin Endocrino Metab 2014;99:3521-3526. Epub 2014 Jul 8

7. Connelly KJ, Boston BA, Pearce EN, Sesser D, Snyder D, Braverman LE, Pino S, LaFranchi SH. Congenital hypothyroidism caused by excess prenatal maternal iodine ingestion. J Pediatr 2012;161:760762. Epub 2012 Jul 27

8. Nepal AK, Suwal R, Gautam S, Shah GS, Baral N, Andersson M, Zimmermann MB. Subclinical Hypothyroidism and Elevated Thyroglobulin in Infants with Chronic Excess lodine Intake. Thyroid 2015;25:851-859. Epub 2015 Jun 1

9. Jooste P, Zimmermann M. Progress towards eliminating iodine deficiency in South Africa: invited review. S Afr J Clin Nutr 2008;21:814.

10. WHO (World Health Organisation), UNICEF (United Nations Children's Emergency Fund), ICCIDD (International Council for Control of lodine Deficiency Disorders). Assessment of iodine deficiency disorders and monitoring their elimination: a guide for programme managers. 3rd Edition ed. Geneva, Switzerland: World Health Organization; 2007.

11. Jooste P, Labadarios $D, N e l H$, Strydom E. lodine content of household salt, drinking water and iodine status of women and children. In: Labadarios D (ed). National Food Consumption Survey-Fortification Baseline (NFCS-FB): South Africa, 2005. Tygerberg, University of Stellenbosch, 2007;387-408.

12. Charlton KE, Jooste PL, Steyn K, Levitt NS, Ghosh A. A lowered salt intake does not compromise iodine status in Cape Town, South Africa, where salt iodization is mandatory. Nutrition 2013;29:630-634. Epub 2012 Dec 28 
13. De La Vieja A, Dohan O, Levy O, Carrasco N. Molecular analysis of the sodium/iodide symporter: impact on thyroid and extrathyroid pathophysiology. Physiol Rev 2000;80:1083-1105.

14. Tazebay UH, Wapnir IL, Levy O, Dohan O, Zuckier LS, Zhao OH, Deng HF, Amenta PS, Fineberg S, Pestell RG, Carrasco N. The mammary gland iodide transporter is expressed during lactation and in breast cancer. Nat Med 2000;6:871-878.

15. Azizi F, Smyth P. Breastfeeding and maternal and infant iodine nutrition. Clin Endocrinol (Oxf) 2009;70:803-809. Epub 2008 Oct 6

16. Yan YQ, Chen ZP, Yang XM, Liu H, Zhang JX, Zhong W, Yao W, Zhao JK, Zhang ZZ, Hua JL, Li JS, Yu XQ, Wang FR. Attention to the hiding iodine deficiency in pregnant and lactating women after universal salt iodization: A multi-community study in China. J Endocrinol Invest 2005;28:547-553.

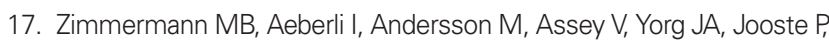
Jukic T, Kartono D, Kusic Z, Pretell E, San Luis TO, Jr., Untoro J, Timmer A. Thyroglobulin is a sensitive measure of both deficient and excess iodine intakes in children and indicates no adverse effects on thyroid function in the UIC range of 100-299 mug/L: a UNICEF/ICCIDD study group report. J Clin Endocrinol Metab 2013;98:1271-1280. Epub 2013 Jan 23

18. Knudsen N, Bulow I, Jorgensen T, Perrild H, Ovesen L, Laurberg P. Serum Tg-a sensitive marker of thyroid abnormalities and iodine deficiency in epidemiological studies. J Clin Endocrinol Metab 2001;86:3599-3603.

19. Zimmermann MB, Andersson M. Assessment of iodine nutrition in populations: past, present, and future. Nutr Rev 2012;70:553-570.

20. UNICEF (United Nations Children's Emergency Fund). Definitions of breastfeeding categories UNICEF UK; 2010.

21. Faber M, Benade AS. Breastfeeding, complementary feeding and nutritional status of 6-12-month-old infants in rural KwaZulu-Natal. S Afr J Clin Nutr 2007;20:16-24.

22. WHO (World Health Organisation). WHO child growth standards: length/height-for-age, weight-for-age, weight-for-length, weight-forheight and body mass index-for-age: World Health Organization; 2006.

23. Pino $S$, Fang SL, Braverman LE. Ammonium persulfate: a safe alternative oxidizing reagent for measuring urinary iodine. Clin Chem 1996;42:239-243.

24. Caldwell KL, Makhmudov A, Jones RL, Hollowell JG. EQUIP: a worldwide program to ensure the quality of urinary iodine procedures. Accred Qual Assur 2005;10:356-361.

25. Andersen SL, Moller M, Laurberg P. lodine concentrations in milk and in urine during breastfeeding are differently affected by maternal fluid intake. Thyroid 2014;24:764-772. Epub 2014 Jan 23

26. Bath SC, Steer CD, Golding J, Emmett P, Rayman MP. Effect of inadequate iodine status in UK pregnant women on cognitive outcomes in their children: results from the Avon Longitudinal Study of Parents and Children (ALSPAC). Lancet 2013;382:331-337. Epub 2013 May 22

27. Dold S, Baumgartner J, Zeder C, Krzystek A, Osei J, Haldimann $\mathrm{M}$, Zimmermann MB, Andersson M. Optimization of a New Mass Spectrometry Method for Measurement of Breast Milk lodine Concentrations and an Assessment of the Effect of Analytic Method and Timing of Within-Feed Sample Collection on Breast Milk lodine Concentrations. Thyroid 2016;26:287-295. Epub 2015 Dec 18.

28. Andrey $D$, Zbinden $P$, Wah MK, Lee W. A routine quality control method for the determination of iodine in human and pet food by ICP-MS. J Anal At Spectrom 2001;22:299-305.

29. Fecher PA, Goldmann I, Nagengast A. Determination of iodine in food samples by inductively coupled plasma mass spectrometry after alkaline extraction. J Anal At Spectrom;13:977-982.
30. Sharpless KE, Lindstrom RM, Nelson BC, Phinney KW, Rimmer CA, Sander LC, Schantz MM, Spatz RO, Thomas JB, Turk GC, Wise SA, Wood LJ, Yen JH. Preparation and characterization of standard reference material 1849 infant/adult nutritional formula. J AOAC Int 2010;93:1262-1274.

31. Torresani TE, Scherz R. Thyroid screening of neonates without use of radioactivity: evaluation of time-resolved fluoroimmunoassay of thyrotropin. Clin Chem 1986;32:1013-1016.

32. Stinca S, Andersson M, Erhardt J, Zimmermann MB. Development and Validation of a New Low-Cost Enzyme-Linked Immunoassay for Serum and Dried Blood Spot Thyroglobulin. Thyroid 2015;25:12971305. Epub 2015 Dec 1

33. Sobrero G, Munoz L, Bazzara L, Martin S, Silvano L, lorkansky S, Bergoglio L, Spencer C, Miras M. Thyroglobulin reference values in a pediatric infant population. Thyroid 2007;17:1049-1054.

34. Zimmermann MB, de Benoist $B$, Corigliano $S$, Jooste $P L$, Molinari L, Moosa K, Pretell EA, Al-Dallal ZS, Wei Y, Zu-Pei C, Torresani T. Assessment of iodine status using dried blood spot thyroglobulin: development of reference material and establishment of an international reference range in iodine-sufficient children. J Clin Endocrinol Metab 2006;91:4881-4887. Epub 2006 Sep 12

35. Secretariat $\mathrm{WHO}$, Andersson $M$, de Benoist $B$, Delange F, Zupan J. Prevention and control of iodine deficiency in pregnant and lactating women and in children less than 2-years-old: conclusions and recommendations of the Technical Consultation. Public Health Nutr 2007;10:1606-1611.

36. Institute of Medicine, Academy of Sciences, USA. Dietary reference intakes for vitamin A, vitamin K, arsenic, boron, chromium, copper, iodine, iron, manganese, molybdenum, nickel, silicon, vanadium and zinc. Washington DC: National Academy Press; 2001.

37. Aakre I. lodine intake and iodine status among lactating women and their children in the Saharawi refugee camps, Algeria. Akershus University College; 2011.

38. Sadou H, Moussa Y, Alma MM, Daouda H. lodine Status of Breastfed Infants and their Mothers after Sixteen Years of Universal Dietary Salt lodization Program in Dosso, Niger. Open Nutr J 2013;7:7-12.

39. Andersson M, Aeberli I, Wust N, Piacenza AM, Bucher T, Henschen I, Haldimann M, Zimmermann MB. The Swiss iodized salt program provides adequate iodine for school children and pregnant women, but weaning infants not receiving iodine-containing complementary foods as well as their mothers are iodine deficient. J Clin Endocrinol Metab 2010;95:5217-5224. Epub 2010 Sep 1

40. Gordon JH, Leung AM, Hale AR, Pearce EN, Braverman LE, He X, Belfort MB, Nelson SM, Brown RS. No difference in urinary iodine concentrations between Boston-area breastfed and formula-fed infants. Thyroid 2014;24:1309-1313. Epub 2014 Jun 16

41. Djemli A, Van Vliet G, Belgoudi J, Lambert M, Delvin EE. Reference intervals for free thyroxine, total triiodothyronine, thyrotropin and thyroglobulin for Quebec newborns, children and teenagers. Clin Biochem 2004;37:328-330.

42. Owen WE, Bunker AM, Straseski JA. Pediatric reference intervals for thyroglobulin using the Beckman Coulter Access 2 immunoassay. Clin Chim Acta 2014;435:40-41. Epub 2014 Apr 26

43. Iwatani Y, Amino N, Tanizawa O, Mori H, Kawashima M, Yabu Y, Miyai $K$. Decrease of free thyroxin in serum of lactating women. Clin Chem 1987;33:1217-1219.

44. Stuebe AM, Meltzer-Brody S, Pearson B, Pedersen C, Grewen K. Maternal neuroendocrine serum levels in exclusively breastfeeding mothers. Breastfeed Med 2015;10:197-202. Epub 2015 Apr 1

45. Bourdoux PP, De Wit SA, Servais GM, Clumeck N, Bonnyns MA. Biochemical thyroid profile in patients infected with the human immunodeficiency virus. Thyroid 1991;1:147-149. 
Osei $\mathrm{J}$ et al.

lodine Status of Infants and Lactating Women

46. Raffi F, Brisseau JM, Planchon B, Remi JP, Barrier JH, Grolleau JY Endocrine function in $98 \mathrm{HIV}$-infected patients: a prospective study. AIDS 1991;5:729-733.

47. Grappin M, Piroth L, Verges B, Sgro C, Mack G, Buisson M, Duong $\mathrm{M}$, Chavanet $\mathrm{P}$, Portier $\mathrm{H}$. Increased prevalence of subclinical hypothyroidism in HIV patients treated with highly active antiretroviral therapy. AIDS 2000;14:1070-1072.

48. Hoffmann CJ, Brown TT. Thyroid function abnormalities in HIVinfected patients. Clin Infect Dis 2007;45:488-494. Epub 2007 Jun 28

49. Madeddu G, Spanu A, Chessa F, Calia GM, Lovigu C, Solinas P, Mannazzu M, Falchi A, Mura MS, Madeddu G. Thyroid function in human immunodeficiency virus patients treated with highly active antiretroviral therapy (HAART): a longitudinal study. Clin Endocrinol (Oxf) 2006;64:375-383.

50. Mulrine HM, Skeaff SA, Ferguson EL, Gray AR, Valeix P. Breast-milk iodine concentration declines over the first 6 mo postpartum in iodinedeficient women. Am J Clin Nutr 2010;92:849-856. Epub 2010 Aug 11

51. Menon KC, Skeaff SA, Thomson CD, Gray AR, Ferguson EL, Zodpey S, Saraf A, Das PK, Pandav CS. The effect of maternal iodine status on infant outcomes in an iodine-deficient Indian population. Thyroid 2011;21:1373-1380. Epub 2011 Oct 26

52. Ordookhani A, Pearce EN, Hedayati M, Mirmiran P, Salimi S, Azizi F, Braverman LE. Assessment of thyroid function and urinary and breast milk iodine concentrations in healthy newborns and their mothers in Tehran. Clin Endocrinol (Oxf) 2007;67:175-179. Epub 2007 Apr 27

53. Hashemipour M, Nasri $P$, Hovsepian $S$, Hadian R, Heidari $K$, Attar HM, Amini M, Moohebat L, Sajadi A, Ajami A. Urine and milk iodine concentrations in healthy and congenitally hypothyroid neonates and their mothers. Endokrynol Pol 2010;61:371-376.

54. Wang Y, Zhang Z, Ge P, Wang Y, Wang S. lodine status and thyroid function of pregnant, lactating women and infants (0-1 yr) residing in areas with an effective Universal Salt lodization program. Asia Pac J Clin Nutr 2009;18:34-40.

55. Zimmermann MB, Jooste PL, Pandav CS. lodine-deficiency disorders. Lancet 2008;372:1251-1262.

56. WHO (World Health Organisation). lodine status worldwide: WHO global database on iodine deficiency. Geneva: Department of Nutrition for Health and Development, World Health Organization; 2004.

57. Jooste PL, Weight MJ, Lombard CJ. lodine concentration in household salt in South Africa. Bull World Health Organ 2001;79:534-540.

58. Wentzel-Viljoen E, Steyn K, Ketterer E, Charlton K. Use salt and foods high in salt sparingly": a food-based dietary guideline for South Africa. S Afr J Clin Nutr 2013;26:105-113.

59. Charlton KE, Steyn K, Levitt NS, Zulu JV, Jonathan D, Veldman FJ, Nel $\mathrm{JH}$. Diet and blood pressure in South Africa: Intake of foods containing sodium, potassium, calcium, and magnesium in three ethnic groups. Nutrition 2005;21:39-50.

60. Harris MJ, Jooste PL, Charlton KE. The use of iodised salt in the manufacturing of processed foods in South Africa: bread and bread premixes, margarine, and flavourants of salty snacks. Int J Food Sci Nutr 2003;54:13-19.

61. Kurtoglu S, Bastug O, Daar G, Halis H, Korkmaz L, Memur S, Korkut $S$, Gunes T, Ozturk MA. Effect of iodine loading on the thyroid hormone level of newborns living in Kayseri province. Am J Perinatol 2014;31:1087-1092. Epub 2014 Mar 28 